\title{
Tracing Hail Stone Impact on External Thermal Insulation Composite Systems (ETICS) - An Evaluation of Standard Admission Impact Tests by Means of High-Speed-Camera Recordings
}

\author{
Veit Steinbauer $_{a}$, Josef Kaufmann $b$, Roger Zurbriggen ${ }_{c}$, Theodor Bühler ${ }_{d}$, Marco Herwegh $_{e}$ \\ anstitute of Geological Sciences, University of Bern, Baltzerstr. 1+3, 3012 Bern, Switzerland, \\ veit.steinbauer@geo.unibe.ch
}

SSwiss Federal Laboratories for Materials Science and Technology EMPA, Laboratory for Concrete and Construction Chemistry, Überlandstrasse 129, 8600 Dübendorf, Switzerland, josef.kaufmann@empa.ch

cAkzo Nobel Chemicals AG, Industriestrasse 17a, 6203 Sempach Station, Switzerland, roger.zurbriggen@akzonobel.com

${ }_{\mathrm{d}}$ Hochschule für Life Sciences, Institut für Chemie und Bioanalytik, Gründenstrasse 40, 4132

Muttenz, Switzerland, theodor.buehler@fhnw.ch

eInstitute of Geological Sciences, University of Bern, Baltzerstr. 1+3, 3012 Bern, Switzerland, marco.herwegh@geo.unibe.ch

Keywords: Impact testing, External Thermal Insulation Composite System ETICS, facade insulation, hail impact, high-speed-camera

\begin{abstract}
Hail impact damage on External Thermal Insulation Systems (ETICS) is increasingly recognized by insurance companies owing to increased storm occurrence frequency and storm intensity. To develop hail resistant ETICS for houses and better understand existing admission tests, high-speedcamera recordings of ice ball impacts at an angle of $45^{\circ}$ and steel ball impacts at angles of $90^{\circ}$ and $45^{\circ}$ were used to characterize the impact process and to derivate the damaging mechanisms of impacts on facades.
\end{abstract}

Recorded surface deformation is characterized by high indentation depth of the impactor and high flexural bending causing high surface parallel strain. Analyses of the impact process allowed the identification of the mechanisms and timing of fracture formation in different regions.

Additionally, differences in the impact process of the European steel ball impact test $\left(90^{\circ}\right.$, ETAG

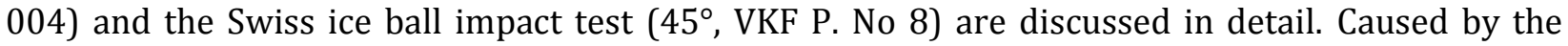
difference in impact angle, the $45^{\circ}$ ice ball impacts lead to lower indentation depth and consequently to lower tensile strain and damage. However, surface parallel movement of the impactor caused the formation of an elongated damage pattern in the $45^{\circ}$ impacts.

To avoid the observed brittle failure behavior, the development of flexible materials with the ability to elastically accommodate impact strains is favorable to reduce hail stone impact damage. 


\section{Introduction}

In recent years, damage caused by more frequent hailstorm occurrence is of economic importance for facade insulation systems, which are increasingly implemented for housings [1]. Using adequate facade insulation, transmission energy loss can significantly be reduced up to $80 \%$ [2]. Therefore, facade insulation is a key component for improving the energy performance of buildings. External Thermal Insulation Composite Systems (ETICS) are the most common measure used for the insulation of facades in Europe [3,4]. The system is popular because it provides thermal insulation at economic prizes as well as a long service life of up to 60 years [5]. Materials with a low thermal conductivity coefficient, like expanded polystyrene (EPS) or rock wool, are used to insulate buildings, as these materials reduce the heat transport and therefore optimize the costs for heating and cooling.

As the insulation materials used in ETICS are soft and vulnerable, their surface is protected from weathering influences by a render system. The ETICS (Figure 1) is composed of (1) an insulation plate fastened to the external house wall by adhesive and mechanical bolts, (2) a base coat (mortar), (3) a fibre glass mesh reinforcement embedded in the base coat and (4) a polymeric top coat (surface finish), sometimes being applied together with a primer for improved adherence to the base coat [6-8]. In this study we investigated cement based base coats, which are available as dry mortars.

a)

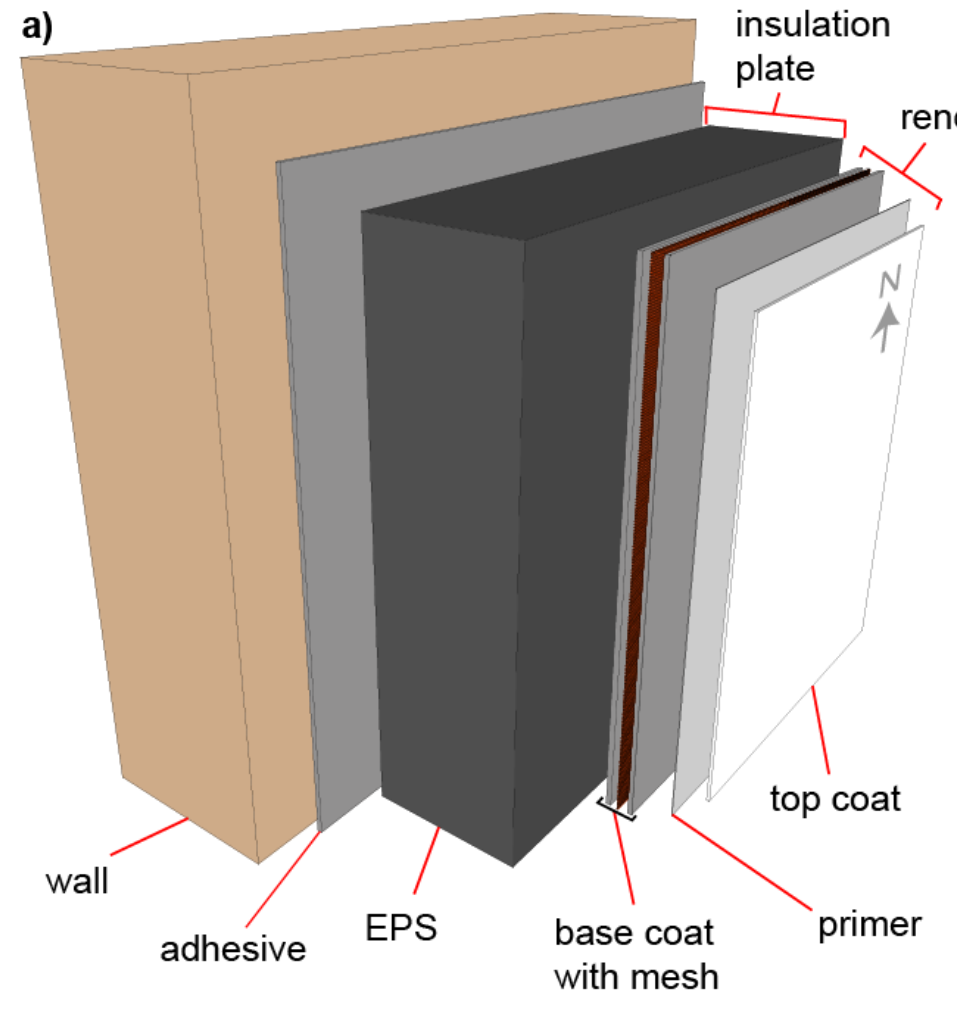

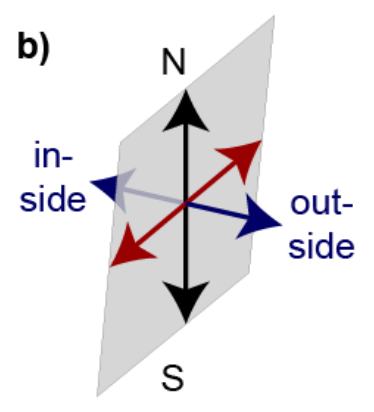

c)

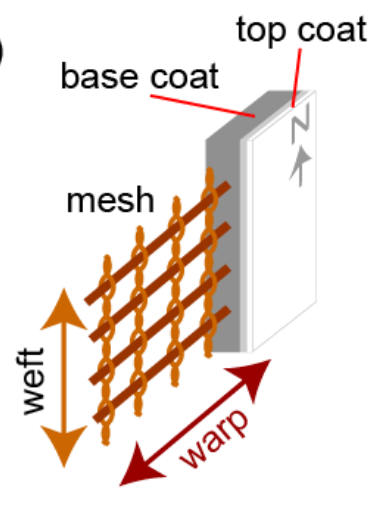

Figure 1: (a) Design of External Thermal Insulation Composite Systems (ETICS) as used in this study, consisting (from wall to outside) of an adhesive layer $(2 \mathrm{~mm})$, an insulation plate (expanded polystyrene EPS, $80 \mathrm{~mm}$ ), a base coat ( $4 \mathrm{~mm}$ ) with reinforcement mesh and a top coat (layer thickness $1.5 \mathrm{~mm}$ ). (b) Sample orientations used in this study: North direction toward the roof and inside toward the house wall. (c) Close up of the render showing the reinforcement mesh string orientation. 
ETICS play a key role in the struggle against climate change [9-11], as heating of houses makes up to about one third of the total energy consumption in countries on the northern hemisphere (e.g. $28 \%$ in Switzerland; [12]). However, severe damage to ETICS facades has been reported with the increasing frequency and intensity of heavy hailstorms in recent years [13-17]. Hail induced depressions and cracks are not only an optical degradation, but also a functional damage of the protective render system $[18,19]$. Resulting water intake may particularly lead to biodeterioration (like mould formation), which can ruin the entire facade $[5,6,20]$. The development of ETICS with an increased hail impact resistance is thus important in order to guarantee a long service life under the currently changing climatic conditions. Natural hail stones are described as spherical lumps with diameters of 0.5 to $10 \mathrm{~cm}$ (under extreme conditions even up to $18 \mathrm{~cm}$ ) and weights of 0.1 to $500 \mathrm{~g}$ [21]. Final velocities of hail stones before impact are in the range of 10 to $50 \mathrm{~m} / \mathrm{s}$ leading to impact energies of 0.01 up to $100 \mathrm{~J}$ (in extreme events even up to $1000 \mathrm{~J}$, [21]). To test hail resistance of facades, two setups were established in the past:

According to the ETAG 004 [22], the impact resistance of ETICS is tested with a steel ball impactor indenting perpendicular to the surface. In this simple setup, experiments are conducted with steel balls of $0.5 \mathrm{~kg}$ at a fall height of $0.61 \mathrm{~m}$ or $1 \mathrm{~kg}$ from a height of $1.02 \mathrm{~m}$ corresponding to impact energies of 3 and $10 \mathrm{~J}$, respectively. In Switzerland and Austria a more sophisticated approach is followed using ice balls with different diameters and speeds. They are shot at an angle of $45^{\circ}$ onto the ETICS (VKF P. No. 8, [23]). A multi-step classification scheme with different ball sizes and speeds is applied to judge the suitability of facade products. In our study three different impact test setups (steel ball $90^{\circ}$, steel ball $45^{\circ}$ and ice ball $45^{\circ}$ ) are implemented. [24] did a detailed comparison of the two admission test setups and provides a microstructural analysis of impact structures at the surface and within ETICS as a function of the impactor material (steel vs ice), its impact angle and energy. With increasing impact energy, first fractures are forming internally in the base coat below the impactor (central fractures below the mesh and spalling fractures) followed by circular ring fractures at the surface and mesh parallel fractures. The depression visible at the surface is caused by shortening in the upper part of the EPS.

This study complements these impact damage quantifications [24], by focusing on the dynamic evolution. A high-speed-camera was used to record the impact in order to gather detailed information on the process of indentation and to link these observations with the resulting fracture pattern allowing to unravel the processes of damage formation. In the first part of this paper the recorded impact process (3.1.) and the resulting surface deformation (3.2.) as well as measured values like the impact energy, contact area (3.3.) and impact force (3.4.) will be described in detail. In the second part the differences in the three test setups (4.1.) will be discussed and the surface damage formation processes (4.2.) and the damaging mechanisms derivated (4.3.).

The aims of this manuscript are twofold: First, the methodology allows for the first time to quantitatively evaluate and compare testing procedures used in the European Union (steel ball $90^{\circ}$, ETAG 004, [22]) and Switzerland (ice ball 45, VKF P. No. 8, [23]) by directly tracing the impact process. Second, we particularly focus on the temporal dynamics of the impact and the resulting mechanical loads for the materials in order to identify optimization potential for hail resistance of the system. 


\section{Methods}

\subsection{Materials and sample preparation}

ETICS are multi-layer composite materials consisting of i) an adhesion layer attaching the insulation to the house wall, ii) the insulation layer (in this study expanded polystyrene, EPS) and iii) the protective render system (Figure 1). The render layer consists of a cementitious base coat with an embedded reinforcement mesh, a primer and a polymer based top coat. Materials and layer thicknesses as used in this study are presented in Table 1. Materials were chosen to resemble a typical ETICS as also used in comparable studies [7,24,25].

ETICS samples were produced in dimensions of $1 \mathrm{~m} \times 0.5 \mathrm{~m}$ placed in a vertical frame for application of the render layers. Throughout all experiments, samples were oriented with the warp sting of the reinforcement mesh pinning toward the roof. This direction was indicated as "N" (North, also referred to as above) direction on the samples (Figure 1) to ensure a reproducible orientation at the impact tests $\left(45^{\circ}\right.$ impacts were shot from $\mathrm{N}$ direction). Sample preparation was carried out by a professional workman following a predefined procedure in analogy to the application on construction site. The base coat was first mixed (mixing of dry mix and water, $45 \mathrm{~s}$ propeller stirring, 5 min maturation period, $15 \mathrm{~s}$ re-stirring by hand). Then, the base coat was trowelled using a toothed trowel (type M1;[26]). After 3 minutes waiting, the reinforcement mesh was placed and incorporated in the base coat by a smoothing trowel. One week later, the primer and another day later the readily mixed top coat were applied. A storage of four weeks at $23 \mathrm{C}$ and $50 \%$ relative humidity followed. Material and preparation procedure were the same as in [24].

Table 1: Materials used in this study.

\begin{tabular}{clcl}
\hline Layer & Materials and Formulations & wt.\% & Function \\
\hline top coat (TC) & Styrene acrylate & 14.00 & Polymer binder \\
$1.5 \mathrm{~mm}$ & Calcium carbonate $<1.5 \mathrm{~mm} \&$ mica & 74.00 & Filler \\
& Others & 4.25 & \\
& Water & 7.75 & \\
\hline base coat (BC) & Portland cement CEM I 52.5 N & 34.00 & Mineralic binder \\
3mm & Calcium hydroxide & 3.00 & Mineralic binder \\
& Calcium carbonate 0.09-0.4 mm & 39.55 & Filler \\
& Calcium carbonate 0.4-0.8 mm & 20.00 & Filler \\
& Zn-stearate & 0.15 & \\
& Cellulose ether & 0.30 & \\
& Redispersible polymer powder & 3.00 & \\
& Water & 23.00 & \\
\hline reinforcem. mesh & Glass fiber mesh, mesh width 4 x 4 mm & \\
\hline insulation $8 \mathrm{~cm}$ & Expanded polystyrene (EPS), swissporLAMDA light, $15 \mathrm{~kg} / \mathrm{m}^{3}$ \\
\hline
\end{tabular}




\subsection{Impact experiments}

Three different impact test setups were studied (Figure 2). A steel ball impact test according to the European standard (ETAG 004, [22], 90 impact angle) as well as a slightly modified version of this test setup ( $45^{\circ}$ impact angle) was compared to the Swiss ice ball impact test (VKF P. No. 8, [23], 45 impact angle). The modified $45^{\circ}$ steel impact test enabled to study the influence of the impactor material.

In the impact test in accordance with ETAG 004 a steel ball impactor of $0.5 \mathrm{~kg}$ (diameter $5 \mathrm{~cm}$ ) in free fall with an impact angle of $90^{\circ}$ was used (thereafter steel ball $90^{\circ}$, Figure 2a). The impact energy $\mathrm{E}$ is controlled by the falling height $\mathrm{h}$ and the mass $\mathrm{m}$ of the ball (eq. 1). Despite the ETAG 004 guideline, a free variation of impact energies was applied. A gutter pipe with a diameter of $5.5 \mathrm{~cm}$ was used to guide the ball. In all impact test setups the sample plate was fixed to a stiff nail board in order to prevent uncontrolled vibrations and related energy absorption.

$$
\text { (1) } E_{\text {pot }}=m \cdot g \cdot h
$$

In a second approach, the impact test setup in accordance with ETAG 004 was adapted by using an angle of only $45^{\circ}$ by inclining the sample (thereafter steel ball $45^{\circ}$, Figure $2 \mathrm{~b}$ ). This steel ball test is thus a mixture of the two standard admission test setups.

While the test setup of European standard uses steel balls as impactors, in the impact tests in accordance with VKF P. No. 8 ice balls with a diameter of $40 \mathrm{~mm}(\sim 31 \mathrm{~g})$ were shot at the sample surface at an angle of $45^{\circ}$ (thereafter Ice ball $45^{\circ}$, Figure 2c). The test mimics the conditions during a hail storm better than the steel ball test, as it uses more realistic conditions. Impactor material (porosity free lab ice, density $\left.8.71 \mathrm{~g} / \mathrm{cm}^{3}\right)$, impactor speed $\left(8-30 \mathrm{~m} / \mathrm{s}\right.$ ) and impact angle $\left(45^{\circ}\right)$ are in this admission test chosen to be close to typical hail. However, as it has to be reproducible and feasible, it still leaves out several features like the irregular shape and surface of a hail stone, multiple impacts at one spot, different impact angles and fast changes in temperature during a hail storm.

An air gun was used to accelerate the ice ball for impact resulting in higher impact speeds than at the steel ball setup. No variation of impactor sizes was applied in order to obtain comparable results at the different impact energies. Immediately before impact testing, the sample surface was wetted to simulate rain in the case of ice ball experiments.

All tests were carried out in an energy range between 2 and $15 \mathrm{~J}$, as this is the range in which damage at ETICS occurs. A minimum distance of $12.5 \mathrm{~cm}$ between single impact spots on the ETICS boards was chosen to prevent interaction of the damage. 


\section{a) steel ball $90^{\circ}$}

\section{b) steel ball $45^{\circ}$}

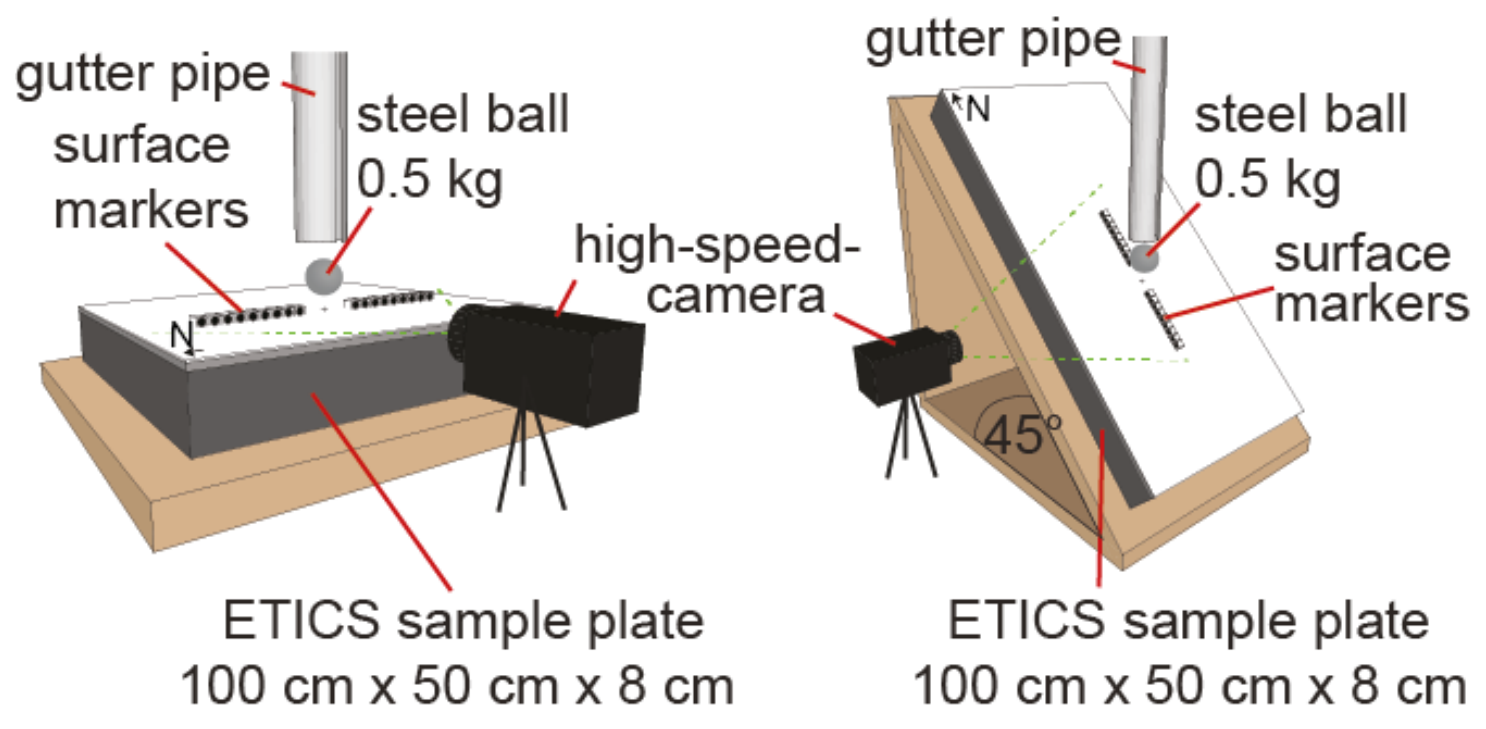

\section{c) ice ball $45^{\circ}$}

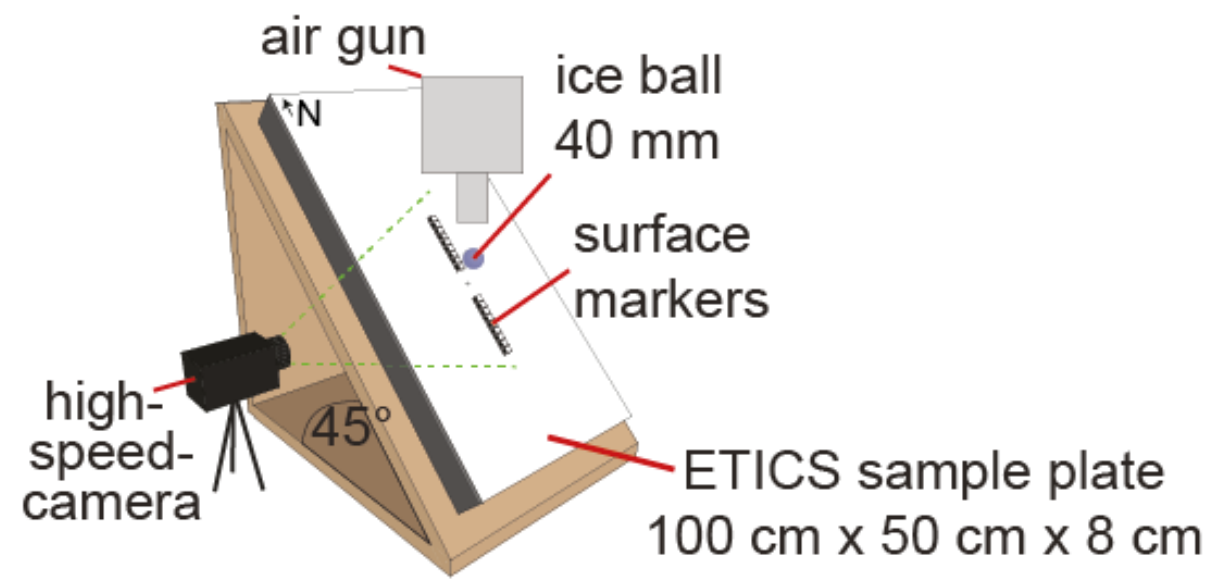

Figure2: Impact test setup for high-speed-camera recordings. (a) Steel ball $90^{\circ}(50 \mathrm{~mm}$, according to ETAG 004), (b) Steel ball $45^{\circ}$ (50 mm), (c) Ice ball $45^{\circ}$ (40 mm, according to VKF Prüfbestimmung No. 8).

\subsection{High-speed-camera recordings}

The impact was recorded using a Motion Pro Y4 high-speed-camera (6000 frames per second) positioned perpendicular to the sample edge (perpendicular to the warp string direction of the reinforcement mesh) in about $50 \mathrm{~cm}$ distance to the impact center (positioning see Figure 2). To be able to follow the deformation of the sample surface during impact, markers aligned on the boards in 3 to $10 \mathrm{~cm}$ distance left and right of the impact center, with $1 \mathrm{~cm}$ distance in between each of them, were added (Figure 2).

The movement of the ball and of the markers before, during and after the impact were automatically traced for each frame (1/6 ms) using the software Motion Studio Pro V. 2.10 and Tracker V. 4.87. 
This setup allowed the calculation of the velocity and hence the kinetic energy of the ball (eq. 2) as well as the reconstruction of surface deformation for each time increment of 1/6 milliseconds.

$$
\text { (2) } \quad E_{\text {kin }}=\frac{1}{2} \cdot m \cdot v^{2} \quad(m=\text { mass, } v=\text { velocity })
$$

Estimated measurement error for the vertical position of each marker was $<0.1 \mathrm{~mm}$. At the impact location no markers could be placed, thus, the movement of the surface was interpolated from the movement of the impactor and the neighboring markers. This interpolation was done by analyzing the shape of the surface in the vicinity of the impact center in the camera images. The contact area between ball and sample was visually estimated from the images. This method is associated with some uncertainty, but nevertheless provides a reasonable estimate for the contact area. The impact force $\mathrm{F}$ was calculated from the deceleration a of the impactor and it's mass m (eq. 3).

(3) $\quad F=m \cdot a$

\section{Results}

\subsection{Visual tracing of the impact process}

High-speed-camera recordings allow a detailed observation of the impact dynamics for the three different setups (three selected images for each setup are given in Figure 3 ). The impact process of the steel ball at $90^{\circ}(\mathrm{a})$, the steel ball at $45^{\circ}(\mathrm{b})$ and the ice ball at $45^{\circ}$ (c) can be described as follows:

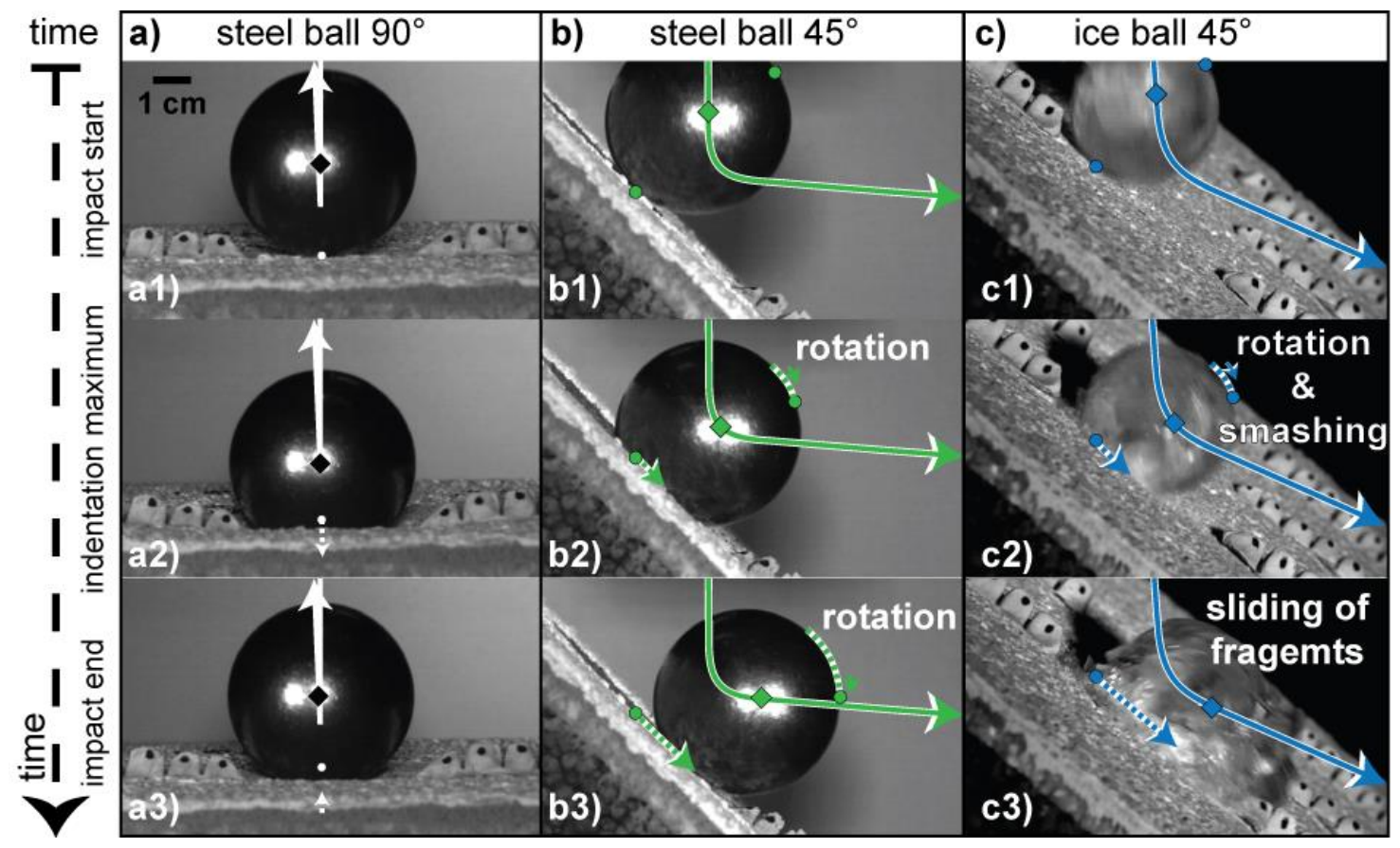

Figure 3: High-speed-camera recordings of (a) steel ball at $90^{\circ}$ (10 J impact energy), (b) steel ball at $45^{\circ}(10 \mathrm{~J})$ and, (c) ice ball impact at $45^{\circ}$ impact angle (11 J).

1. Steel ball, $\mathbf{9 0}^{\circ}$ : After touching the sample surface (impact start) the impactor indents into the sample, bending the ETICS surface inwards. As the indentation depth increases, the indentation speed slows down until the impact stops completely at the point of maximum 
indentation depth (indentation maximum). The indentation phase has ended and the impactor is elastically pushed back by the sample in the repelling phase. The exit angle for the $90^{\circ}$ steel ball test is $90^{\circ} \pm 3^{\circ}$ relative to the sample surface. Hence indentation and repelling geometry are axis symmetric and therefore identical.

2. Steel ball, $45^{\circ}$ : In the $45^{\circ}$ impact, the impactor hits the sample surface at an impact angle of $45^{\circ}$ relative to the sample surface. Like in $90^{\circ}$, the impactor bends the ETICS surface inward, slowing down toward the indentation maximum during the indentation phase. However, in the $45^{\circ}$ test, in addition to the orthogonal movement, the steel ball moves parallel to the sample surface during impact. The ball slides along the ETICS surface during the first 0.1-0.3 ms before it starts to rotate. By rolling a distance of $1-3 \mathrm{~cm}$ is covered before leaving the sample at an angle of $40^{\circ} \pm 5^{\circ}$. This movement along the sample surface leads to a shift of the contact area along the indentation direction (and thus the stress field).

3. Ice ball, $\mathbf{4 5}^{\circ}$ : The ice ball movement is comparable to the impact in (b). However, in comparison to steel, the much softer ice shatters at impact energies $>6 \mathrm{~J}$ into few pieces, and above $10 \mathrm{~J}$ it is entirely shattered. The shattered pieces splash and slide along the sample surface at a low angle. Exiting angle is $40^{\circ} \pm 5^{\circ}$ for non-fragmented ice balls and $25^{\circ} \pm 15^{\circ}$ for fragmented ice pieces.

\subsection{Evolution of the surface deformation}

Surface markers allowed tracing the deformation of the surface caused by the impact of the steel or ice ball (Figure 4). Surface profile lines deducted from the markers provide a clear image of the depression shape during impact and allow the calculation of the elongation of the sample surface (strain). Averaged elongation at maximum indentation depth is about 1.5 times higher for the $90^{\circ}$ ( $2.0 \mathrm{~mm} / 200 \mathrm{~mm}$ for $10 \mathrm{~J})$ compared to the $45^{\circ}(1.2 \mathrm{~mm} / 200 \mathrm{~mm}$ for $10 \mathrm{~J}$ steel ball, $1.5 \mathrm{~mm} /$ $200 \mathrm{~mm}$ for ice ball $11 \mathrm{~J}$ ) setups.

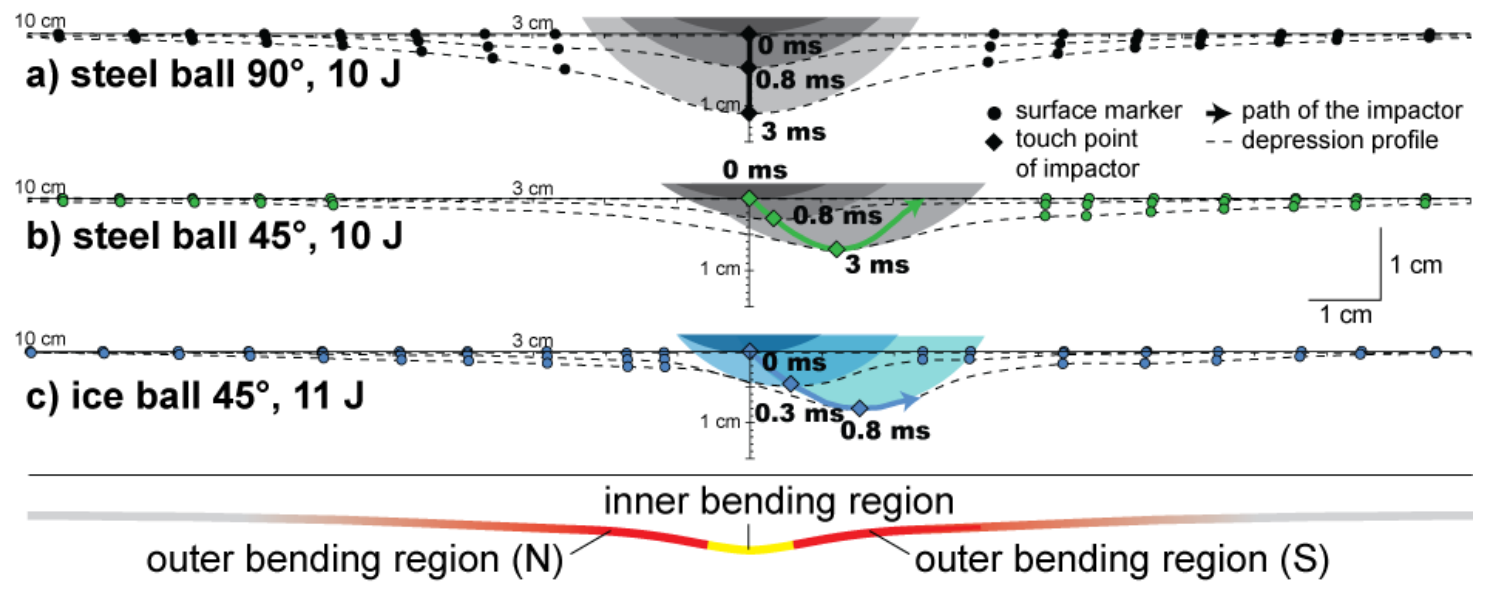

Figure 4: Change in surface profile with time during impact given for the three different test setups (ac). Impactor colors' brightening indicates different positions in time. Parts between the surface markers (black dotted lines) have been extrapolated.

The impact depression contains two bending regions with different bending directions - the inner region situated directly below the ball is bending concave (toward the ball) and the outer region convex (bending toward the EPS; see lower part of Figure 4). At its center the slope of the inner region follows the impactor's shape, but flattens toward the rim. The slope of the convex outer 
region is largest close to the transition from the inner region, but decreases toward the rim till the flat original surface is reached.

The radius of the depression increases during the impact (Figure 4). At the beginning of the impact, surface bending is concentrated to a small zone close to the ball, but with growing impact depth, the radius of the depression increases influencing the sample surface in a radius of up to $8 \mathrm{~cm}$ around the impact center (for $10 \mathrm{~J}$ impact energy, Figure 4a).

The depression profile in the steel ball test at $90^{\circ}$ is symmetric throughout the whole impact (Figure $4 a)$.

At an angle of $45^{\circ}$ the ball moves along the surface during impact (Figure $4 b \& c$ ). Therefore the depression profile is asymmetric, but shifts together with the impactor, leading to the deepest depression south of the point of first contact. The depression profile is also showing the two bending regions, but their position is shifting together with the ball. Maximum depression depth at $10 \mathrm{~J}$ and $11 \mathrm{~J}$, respectively, is $7 \mathrm{~mm}$ for both, steel and ice ball (Figure $4 \mathrm{~b}$ and c) at $45^{\circ}$ but lower than the maximum depression at the $90^{\circ}$ setup, which is $11 \mathrm{~mm}$ at $10 \mathrm{~J}$.
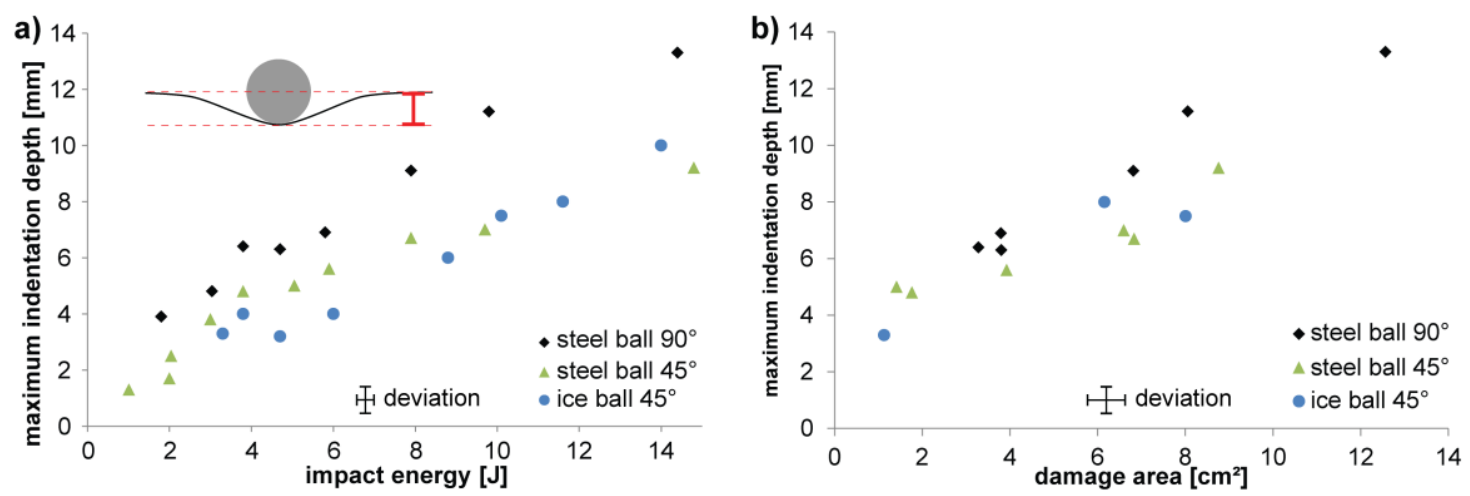

Figure 5: (a) Maximum indentation depth (point of maximum indentation of the impactor) in dependence of impact energy. Higher values are reached for $90^{\circ}$ than for $45^{\circ}$ impacts; (b) degree of surface damage (damage area $=$ area of visible surface depression, ellipsis of depression width and depression length) in dependence of maximum indentation depth. At equal indentation depth, surface damage is higher in the $45^{\circ}$ than in the $90^{\circ}$ impacts. Maximum deviation is given by the precision of the method of determination.

This difference in maximum indentation depth of the $90^{\circ}$ and the $45^{\circ}$ impact setups is true for all measured impact energies (Figure 5a). The $90^{\circ}$ impacts result in significantly higher impact depths than the $45^{\circ}$ impact experiments. At equal impact energy up to 20-40\% (10 J: 2-3 mm) deeper impact depths are reached. The impact angle influences the resulting damage area (damage area $=$ area of visible surface depression, ellipsis of depression width and depression length). Equal indentation depth leads to larger surface damage area for $45^{\circ}$ impacts (Figure $5 \mathrm{~b}$ ) compared to $90^{\circ}$ ones. This enlarged damage area is caused by the elongated damage pattern during the oblique $45^{\circ}$ impact and is more pronounced at higher impact energies (Fig. 5b). Nevertheless, at equal impact energy, caused by the higher indentation, the damage area and the overall damage at $90^{\circ}$ is higher. Tracing the evolution of the deformation of the surface at different positions allows the detection of the detailed timing of different impact steps. Figure 6 and Figure 7 show the vertical movement of the markers together with the movement of the ball for 2, 4 and 10/11 J impact energy as a function of time. 

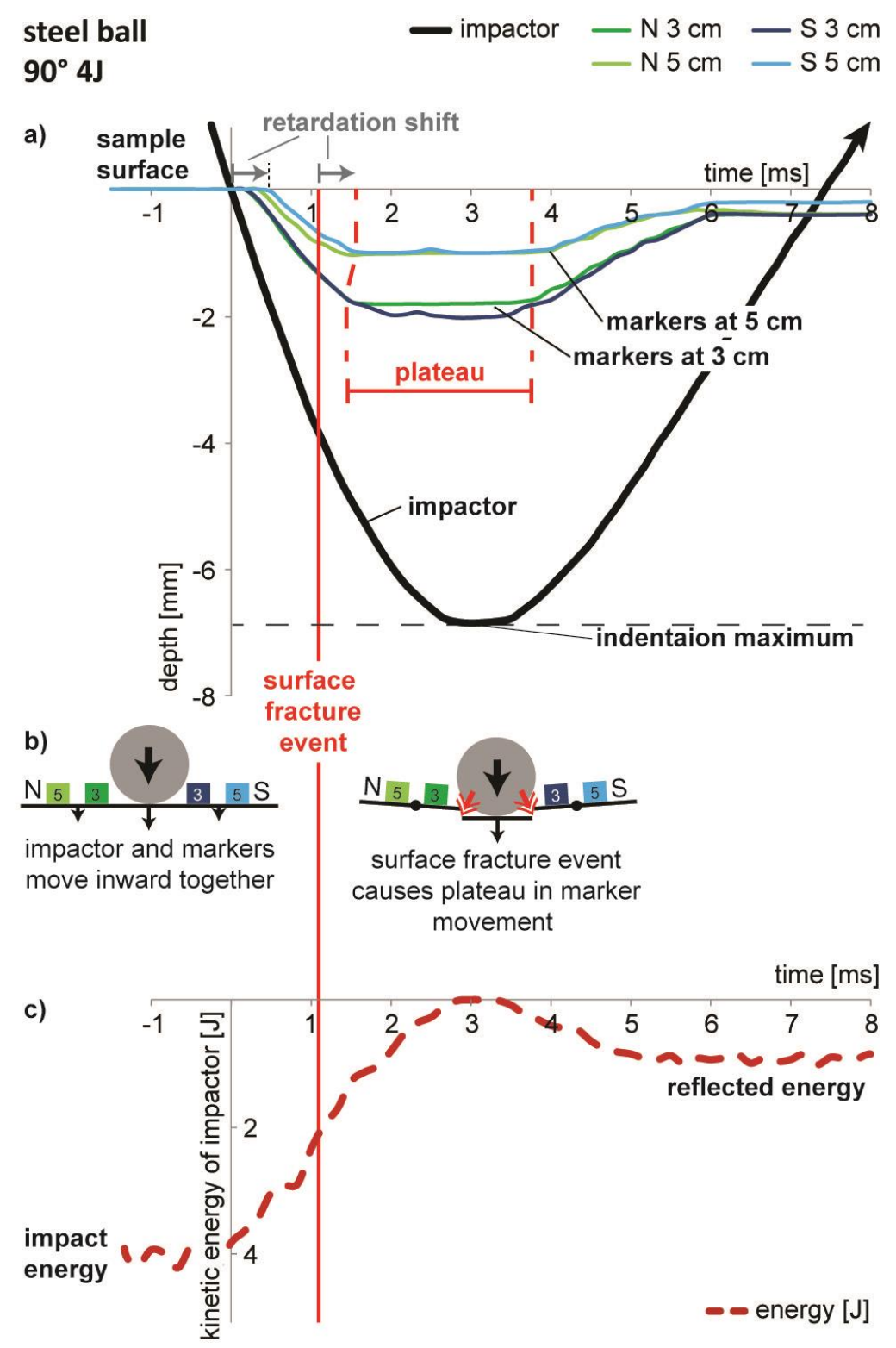

Figure 6: a) Vertical (= perpendicular to sample surface) surface displacement (depth into the sample) at the impactor ball position (thick black line) and at 3 and $5 \mathrm{~cm}$ distance from impact center (blue and green lines). Shown as an example is a $4 \mathrm{~J}$ steel ball impact at an impact angle of $90^{\circ}$. The formation of the main surface ring fracture (surface fracture event) is indicated by the red line and followed by a plateau in the markers movement. Note the shift in the timing of the deformation plateau due to the distance from the impactor to the markers position indicated by black arrows (retardation shift) leading to a retarded signal of the surface fracture event in the markers movement. b) Illustration of the position of the surface markers and the relative movement before (left) and after the surface fracture event. Note the decoupling of the inner (below the impactor) from the outer part, which is indicated by the stopping of the inward movement of the markers (plateau). c) Recorded absolute kinetic energy of the impactor before (impact energy), during and after the impact (reflected energy). An overview of the results of the different impact setups at different impact energies is given in Figure 7. 

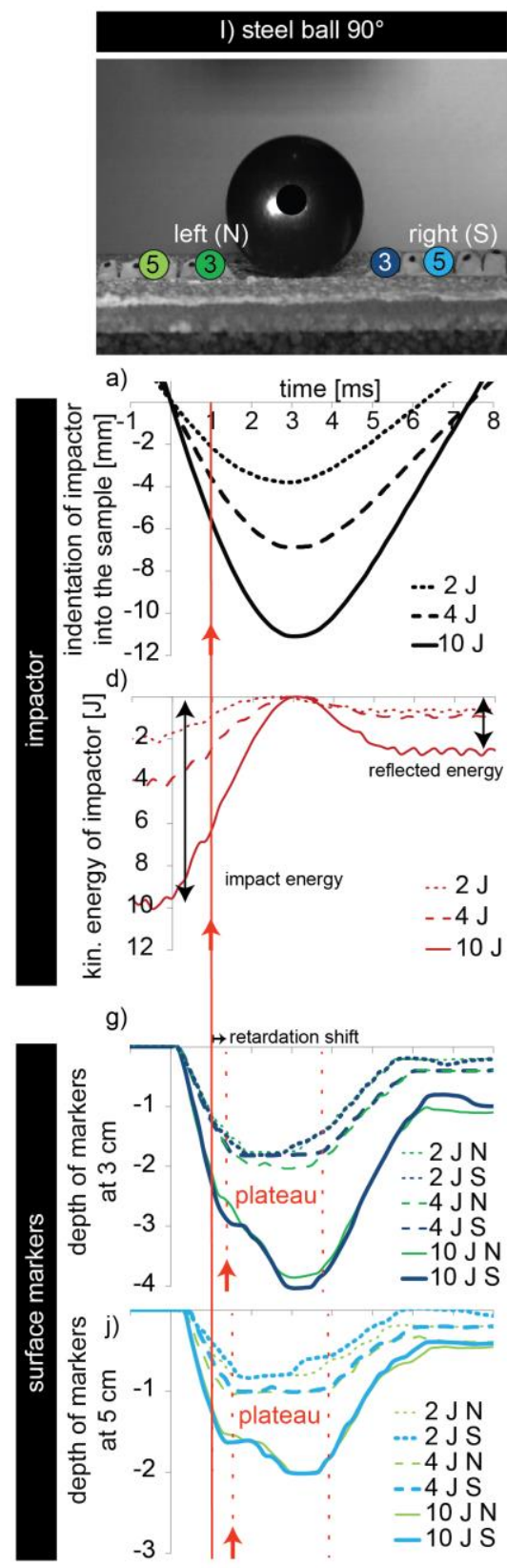

surface fracture event
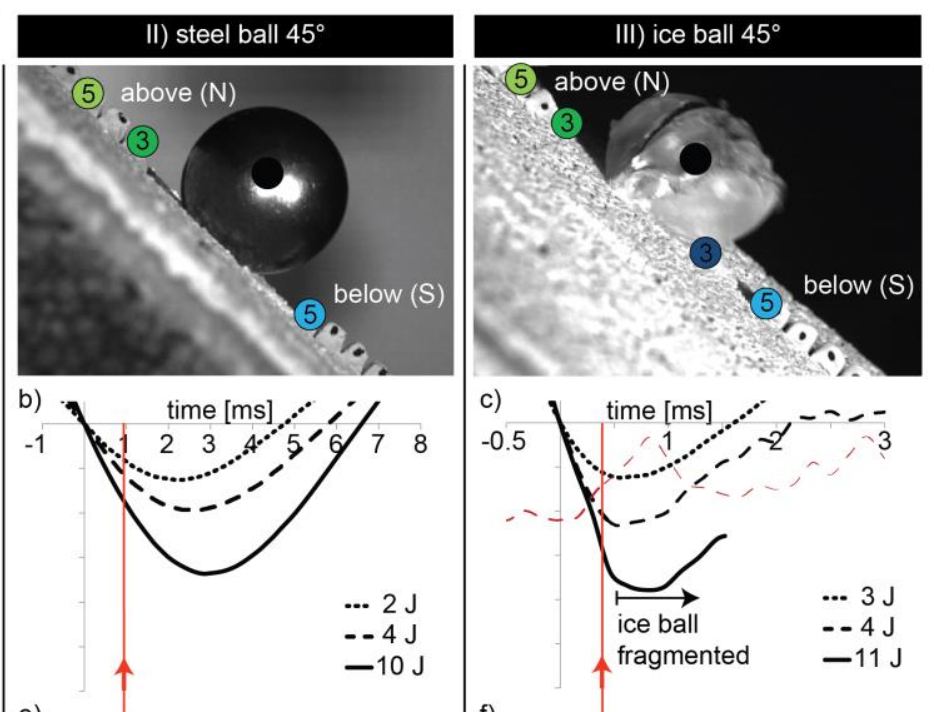

e)

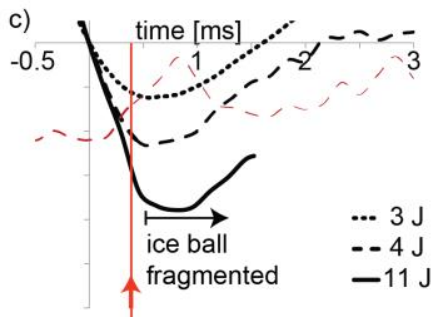

f)

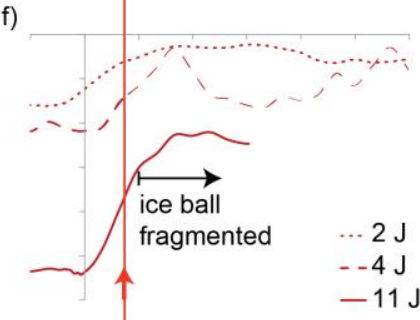

h)
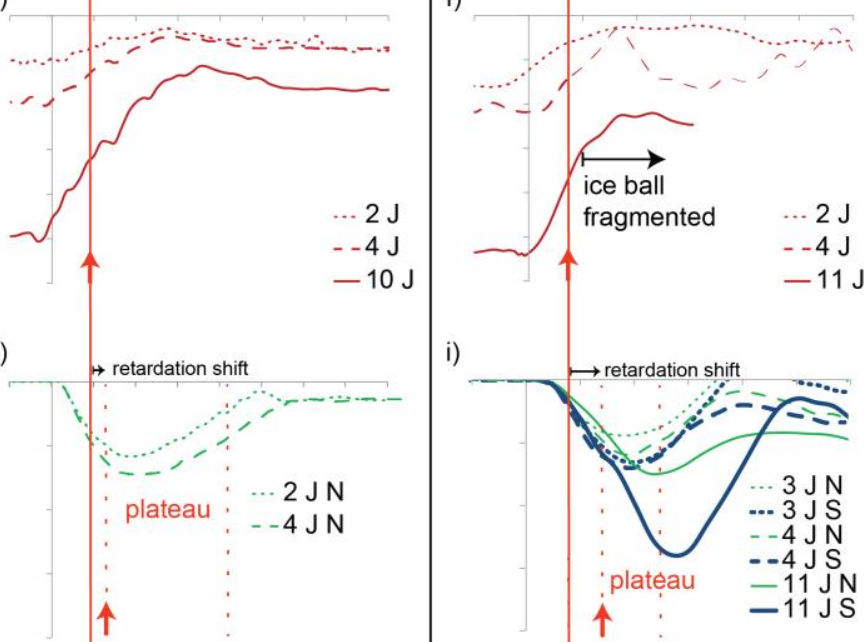

I)

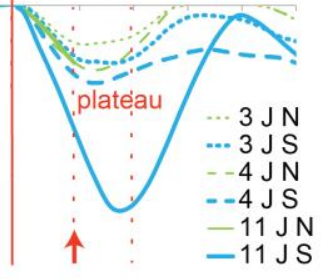

signal of surface fracture event

Figure 7: Vertical (= perpendicular to sample surface) surface displacement (depth into the sample) at the impactor ball position (a-c) and in 3 and $5 \mathrm{~cm}$ distance from impact center $(\mathrm{g}-\mathrm{l})$ as well as the recorded absolute kinetic energy of the impactor (d-f). Shown are the three test setups at different impact energies (I-III). The formation of the main surface ring fracture (fracture event) is indicated by the red arrows. Note the shift in the timing of the deformation plateau due to the distance from the impactor to the markers position indicated by black arrows (retardation shift) leading to a retarded signal of the surface fracture event in the markers movement. In the case of the steel ball at $45^{\circ}$ the markers $3 \mathrm{~cm}$ below the impactor could not be measured. 
1. Steel ball, $90^{\circ}$ : For steel ball tests at $90^{\circ}$, with an impact energy of $2 \mathrm{~J}$, the surface markers follow the movement of the ball throughout the impact (Figure 7 I a,d,g and j, dotted lines). At impact energies $>2 \mathrm{~J}$, surface markers initially also follow the movement of the ball, but start to deviate after $1.5 \pm 0.5 \mathrm{~ms}$ (Figure $7 \mathrm{a}, \mathrm{d}, \mathrm{g}$ and $\mathrm{j}$, dashed and filled lines). While the ball continues to penetrate the sample, the surface markers do show no further deflection causing the deformation plateau (Figure 7g). The onset of the plateau conciliates with the evolution of the surface fractures described in Steinbauer et al, 2016. Note that the surface markers' movement at different distances from the impact center is steadily slightly delayed regarding the impactor's movement caused by the signal velocity in the ETICS material (time signal needs to travel the distance from impactor/fracture toward the markers, indicated as retardation shift in Figure 7). After $4 \pm 0.5 \mathrm{~ms}$ the makers follow the reflected ball in its outward movement terminating the plateau. For high-energy impacts $(10 \mathrm{~J})$, the plateau is temporarily interrupted after about at $2 \pm 0.5 \mathrm{~ms}$. In steel ball tests the maximum indentation depth (indentation maximum) is reached after indentation times of about $2.8-3.0 \mathrm{~ms}$. The deceleration of the ball in the indentation phase is significantly higher than the later acceleration in the repelling phase. The influence of the impact energy on the timing of events is rather small.

2. Steel ball, $\mathbf{4 5}^{\circ}$ : In the steel ball test at $45^{\circ}$ the surface marker tracking lines are similar to the $90^{\circ}$ setup, however, the plateau is less pronounced (Figure 7 II h and k). Due to the lower indentation angle, the ball moves along the sample surface. This lateral indenter movement leads to a time shift in the deflection of the different markers. Surface markers ahead in the movement direction ("below") move further inward, as the ball moves closer to them during the impact progress, whereas surface markers behind the point of first contact ("above") show less vertical movements as the distance to the ball increases. Consequently, the stress and strain field also shifts with the movement of the ball along the sample surface.

3. Ice ball, $45^{\circ}$ : In the ice ball test (at $45^{\circ}$ ) the general impact features are comparable to the $45^{\circ}$ steel ball arrangement. However, all processes and responses occur much faster due to the higher impact speed (Figure 7 III c, f, i and l). Because of its lower weight, at equal impact energy, the speed of the ice ball is 4 times higher compared to the speed of the steel ball in the two other impact tests. In ice ball tests the maximum indentation is reached at about 0.6 $0.8 \mathrm{~ms}$. The formation of the plateau at about $0.5 \mathrm{~ms}$ is less pronounced than in the $45^{\circ}$ steel ball setup, however, the shorter time span leads to a lower resolution of the measurement of the marker position. As the ice ball shatters at about 2/3 of the maximum displacement depth in the case of high-energy impact experiments $(>6 \mathrm{~J})$, their subsequent movements could not be analyzed accurately anymore. The derived data therefore represents the movement of the biggest fragment only.

\subsection{Impact energy}

The measurement of the change in speed of the ball with a temporal resolution of $1 / 6$ milliseconds, allows the calculation and tracing of the kinetic energy of the ball during the impact (Figure 7, bottom row). The kinetic energies of the impactors decrease continuously, without distinct steps, until the maximum impact depth is reached. Then the kinetic energies increase again, but with a lower slope compared to the deceleration stage. In the $90^{\circ}$ test setup, the kinetic energy is zero at the indentation maximum, as the ball is totally stopped by the ETICS. In both $45^{\circ}$ setups, the ball moves forward along the sample surface throughout the whole impact process. In contrast to the $90^{\circ}$ setup, the total kinetic energies in $45^{\circ}$ setups therefore never reach zero values. 
The kinetic energy of the ball before (impact energy) and after the impact (reflected energy) was detected by the use of the high-speed-camera recordings allowing the estimation of the energy loss during impact (Figure 8a). The amount of reflected energy decreases until about $3 \mathrm{~J}$. At higher energies, a constant amount of energy of about $25 \%$ (steel ball $90^{\circ}$ ) and $35 \%$ (steel ball $45^{\circ}$ ) is reflected. This change in the amount of reflected energy coincides with a threshold energy, at which first surface damage occurs (Figure 8b). Comparing the steel ball test setups, the amount of reflected energy in the $45^{\circ}$ setup is around $10 \%$ higher than in the $90^{\circ}$ setup. Ice ball experiments show reflected energies scattering between the results of both steel ball setups. A higher impact speed and the fragmentation of the impactor ball complicated precise measurements of the reflected energy, leading to less accurate results. After fragmentation, the kinetic energy was derived from the analysis of the largest fragment only.
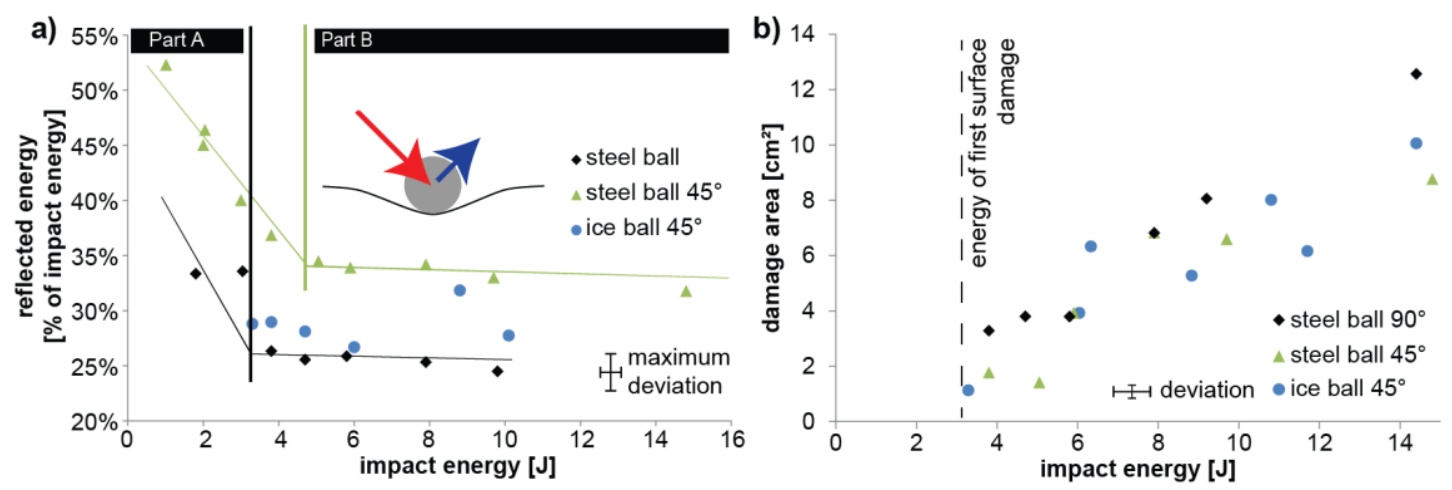

Figure 8: (a) Kinetic energy of the impactor before (impact energy) and after the impact (reflected energy). The amount of reflected energy reaches a plateau upon surface damage formation at a threshold energy of 3-5 J; (b) amount of surface damage (damage area) in dependence of impact energy, first significant surface damages occurred at impact energies higher than $3 \mathrm{~J} .90^{\circ}$ impacts lead to larger damage areas than $45^{\circ}$ impacts. Maximum deviation is given by the precision of the method of determination.
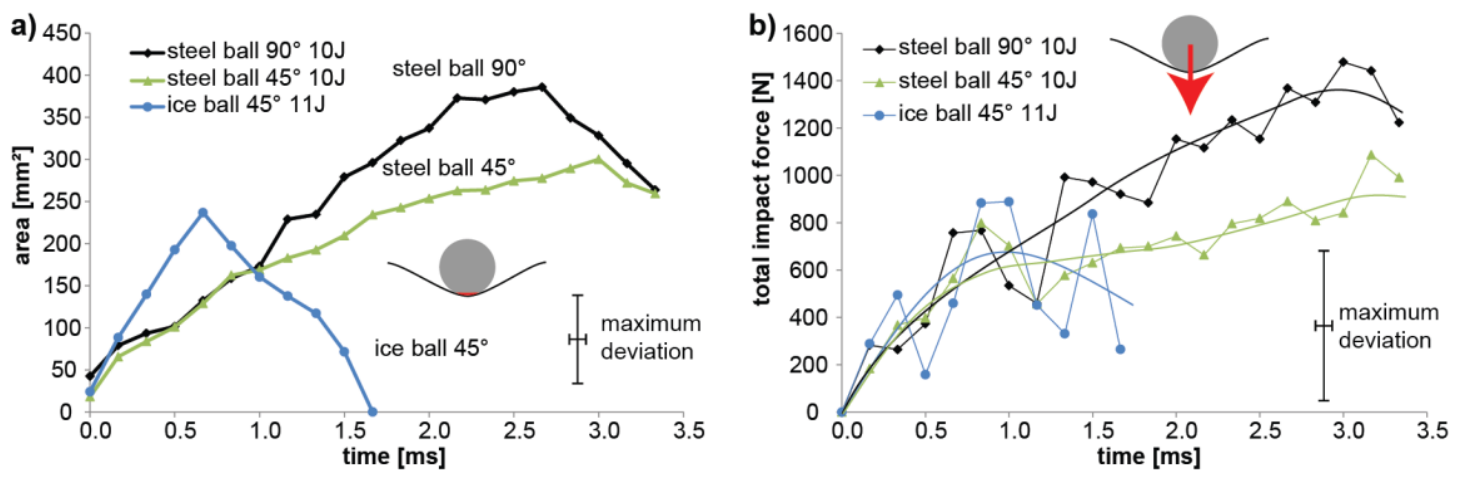

Figure 9: Impact properties for the three test setups. (a) Contact area of impactor and sample during impact. Data extracted from high-speed-camera recordings. (b) Development of impact force (impactor's total push force) during impact. Maximum deviation is given by the precision of the method of determination.

\subsection{Contact area and impact force}

The high-speed-camera recordings also allowed estimating the contact area between ball and sample surface as well as the calculation of the total impact force (Figure 9a and b). These 
calculations were used to estimate the compressive stress (see 4.2.). At the beginning of the impact, the contact area rises first rapidly then slower toward the maximum value, which is reached at the maximum indentation depth. For all three setups, the impact force shows an equally fast increase at the very beginning of the contact, followed by a slower increase till the maximum value is reached at the maximum indentation depth. In the $90^{\circ}$ steel ball setup, the impact force is higher than in both $45^{\circ}$ setups. Owing to the estimation procedure and related uncertainties, one should be aware that the estimates are subject to a significant degree of uncertainty (see figure 8).

\section{Discussion}

\subsection{Differences in the impact behavior of steel ball $90^{\circ}$, steel ball $45^{\circ}$ and ice ball $45^{\circ}$ tests}

\section{Impactor and surface deformation}

High-speed-camera recordings allow a precise time-resolved characterization of the surface deformation during impact. The most important differences between the impact behavior of the different setups was identified as (1) the impact depth, (2) the depression shape caused by the shift of the ball along the surface at $45^{\circ}$ impacts, (3) the impactor material (steel vs. ice) and (4) the impact duration.

1. Indentation depths: Unexpected high indentation depths ranging from 1.5 to $14 \mathrm{~mm}$ were recorded in all experiments (see Figure 5a). This high indentation leads in the beginning to elastic but with increasing indentation as well to plastic materials reactions resulting in an increasing compressive stress at the contact to the impactor (Figure 9). High indentation also favors high bending and therefore high tensional forces can be expected in bending regions (see 4.3.). At $90^{\circ}$ angles, the impact force consist of the component of the normal to the sample surface only, whereas at the $45^{\circ}$ impact angle the force is divided into a force (i) normal and (ii) parallel to the sample surface. Therefore the normal force, which causes the compression of the sample, is lower at $45^{\circ}$ angles and results in a lower maximum indentation depth (about $30 \%$ lower, Figure 5a) leading therefore to reduced damage in comparison to the $90^{\circ}$ impact. The $45^{\circ}$ setup is closer to impacts of natural hail stone on vertical house facades making the precise relation between damage and impact angle highly relevant for the development of ETICS with improved hail resistance.

2. Depression shape: During indentation, the sample surface deformation (depression) can be divided in two bending regions (Figure 4). The inner region directly below the contact zone directly adopts the shape of the ball, which is rather predefined, particularly in the case of steel ball tests. Further away at the outer region, bending goes in the opposite direction. Owing to the impact-shearing induced by the surface parallel component of the impact force in both $45^{\circ}$ setups the point of highest depression horizontally shifts in direction of the ball movement (Figure $4 \mathrm{~b}$ and $\mathrm{c}$ ). This shift in the regions of highest bending strongly controls the damage pattern (see 4.2.). This shearing-induced damage pattern is relevant for natural hail stone impact, as they mostly occur at intermediate to small impact angles.

3. Impactor material: The ice ball splits at impact energies above $6 \mathrm{~J}$ (Figure 3c1 and c2), whereas in the steel ball experiments the impactor can be regarded as fully elastic but with high EModulus (Figure 3a and b). The compressive strength of artificial lab ice is in the range of 5$10 \mathrm{MPa}$ for the temperature and strain rates expected in our experiments $[27,28]$. In contrast, in natural hailstorms considerable lower compressive strengths of ice with an average of 
0.7 $\mathrm{MPa}(0.1-4.3 \mathrm{MPa})$ were measured by [29]. According to them, the average force during brittle failure imposed by a $30 \mathrm{~g}$ hail stone is $400 \mathrm{~N}$, but shows a wide variety ranging from 100 to $2200 \mathrm{~N}$. Their observation coincides with the fragmentation of our ice balls at $400+/-200 \mathrm{~N}$ (fragmentation of ice ball at about $0.5 \mathrm{~ms}$, see Figure 7c). The fracture strength of ice is reached at $6 \mathrm{~J}$ for a $40 \mathrm{~mm}$ ice ball. Considering the high variation in failure strength observed by [29], natural hail stones might fragment at significantly lower and higher impact forces or may even show no shattering at all. After shattering, a lower compressive stress than in a non-shattered ball would be expected, as parts of the impact energy is consumed by the fracture process. Furthermore, a higher contact area is expected for a fractured ice ball. This would lead to a further reduced impact stress and thus result in reduced impact damage. However, our previous investigations have shown that the resulting impact damage is almost independent from the shattering of the ball [24]. We therefore infer that the main sample damage forms shortly after the impact, while the fragmentation of the ice ball occurs later when compressive stresses high enough to fracture the ice have built up between the ice ball and sample by the increasing compression of the ETICS. A modification of the surface material favoring the shattering of the ice ball directly after contact might lead to an absorption of impact energy and could help to prevent the damage of the ETICS. Apart from the possible shattering of the impactor, the surface properties of steel and ice differ significantly. This leads to different friction behavior at the impactor-sample interface influencing sliding and rotation of the ball at the sample surface. The friction coefficient of ice is expected to be lower leading to lower shear forces. Despite this difference, both materials show an initial stage of short sliding followed by a rotational movement.

4. Impact duration: Due to the differences in the ball mass (impactor material, steel ball $0.5 \mathrm{~kg}$, ice ball $31 \mathrm{~g}$ ), the ice ball impulse and the duration of the impact differs for the three setups. With the steel ball impactor, the impulse p (eq. 4) is at equal impact energy significantly higher compared to the ice ball, most likely leading to higher damages, even so the impact speed is lower.

$$
\text { (4) } p=m \cdot v(m=\text { mass, } v=\text { velocity })
$$

The duration of the contact between the steel balls $\left(90^{\circ}\right.$ and $\left.45^{\circ}\right)$ and the sample surfaces are of almost the same order, whereas the ice ball contact-time is much shorter (Figure 7a,b and c). In general, the timing of the impact process can be regarded as almost constant for a distinct combination of impactor and sample types. Comparing different impact energies, all impact durations increase with increasing impact energy (=impact speed), but differences are quite small. Owing to the higher impact speeds higher strain rates can be expected in the case of ice ball impacts. The higher strain rates influence the strain rate dependent material properties (e.g. the yield point) of the materials in the sample as well as affect the stress and strain distribution during impact influencing thus damage formation. Yield points at higher stress and a higher stress concentration can be assumed for ice ball impacts.

\section{Reflected Energy}

Tracing the evolution of kinetic energy during impact (Figure 8a) revealed that two parts can be distinguished: In the first part (high negative slope, part A in Figure 8a) reflected energy decreases with increasing impact energy from about 50-60\% of the impact energy to $25-30 \%$. At these low impact energies $(<4 \mathrm{~J})$ no surface damage is observed, not excluding the accommodation of impact energies in subsurface damage [24]. In the second part (part B in Figure 8a) at energies higher than the threshold energy, only a small part of the impact energy (constantly 25-30\%) is reflected 
elastically. Interestingly, severe surface damage is observed at these impact energies. The percentage of reflected energy is thus correlating tightly to the resulting damage. In the first part indentation and repelling of the impactor is dominated by the mechanical properties of the base and top coat. Increasing internal fracturing leads to a decrease in repelling potential with increasing impact energy, simply because the elasticity decreases with progressive fracture growth and density. Most likely the circular surface fractures that form energies higher than the threshold energy and dissect the entire render system except the mesh lead to a decoupling of the inner part of the render (area within the circular surface fracture) from the outer render, and therefore the elasticity in the second part is mainly dominated by a combination of the elasticity of EPS below the impactor and the intact reinforcement mesh.

The change in slope of the reflected energy is used to classify the degree of damage just by looking at the amount of reflected energy, which can be derived base on the high-speed-camera recordings (see above). Knowing the mathematical function of the negative slope in the first part might actually allow predictions of the unknown damage threshold energy.

In general, the energy that is absorbed (deformation energy) is consumed by non-destructive vibration, friction, heat as well as permanent plastic deformation and fracture formation.

\subsection{Surface fracture formation process}

Visible depressions and circular fractures at the surface represent the main damage patterns resulting from impacts at ETICS [24]. The mechanisms causing this damage can be deduced from the high-speed-camera recordings presented in this study. The following chapters will first link the recorded surface displacements with the damage pattern (4.2.) and then identify the dominating damaging processes (4.3.).

\section{Damages}

The deformation of the surface during impact (Figure 4) is reflected in the distinct fracture geometry that is observed after the mechanical impact. The resulting damage patterns are described in detail in [24]: (i) Depressions: Visible depressions after impact are circular for $90^{\circ}$ impacts, but elliptic for $45^{\circ}$ impacts. Remaining depression depth after impact is for steel balls $90^{\circ} 3 \mathrm{~mm}$ at $10 \mathrm{~J}$, $2 \mathrm{~mm}$ for steel balls $45^{\circ}$ and $2.2 \mathrm{~mm}$ for ice balls at 10 and $11 \mathrm{~J}$ [24]. (ii) Fractures: In all setups one prominent circular surface fracture ("main ring fracture", ca. $1.5-2 \mathrm{~cm}$ wide) is observed. The $45^{\circ}$ impacts additionally show further strong semi-circular fractures with centers shifted 1-1.5 cm in the direction of the impactor's pathway ("secondary surface fractures"). In the $90^{\circ}$ steel ball test at high energies additional less pronounced fractures with a larger radius can be found [24].

\section{Main surface fracture formation}

Tracing surface and ball positions during the impact (Figure 4) is useful to clarify the timing and geometry of fracture formation (Figure 10). The main surface ring fracture forms at an impact depth of 3-4 mm ("main surface fracture event", steel ball $90^{\circ}$ :at about $1 \mathrm{~ms}, 3 \mathrm{~mm}$ impact depth; steel ball $45^{\circ}$ : at about $1 \mathrm{~ms}, 3 \mathrm{~mm}$; ice ball $45^{\circ}$ : at about $0.3 \mathrm{~ms}, 4 \mathrm{~mm}$; indicated by the squares in red in Figure 10 for surface profiles at different time steps (a-c) and in the resulting surface fracture pattern (d-f)). At this time the location of strong concave bending at the shoulders of the depression (outer bending region) corresponds to the observed main surface fractures in this surface region. The strong bending leads to high strain, which induces mode I extension fractures at these positions. For these reasons, we assume that the ETICS surface breaks at penetration depths of the impactor of 3 to $4 \mathrm{~mm}$ (Figure 10).This observation matches to the minimum impact energy, at 
which first surface fractures form. First fractures occur when impact energies reach at least a maximum indentation depth of 3-4 mm (Figure 5b). This indentation depth therefore corresponds to the maximum strain necessary for brittle failure of the render layer at impact conditions.

a) steel ball $90^{\circ}, 10 \mathrm{~J}$

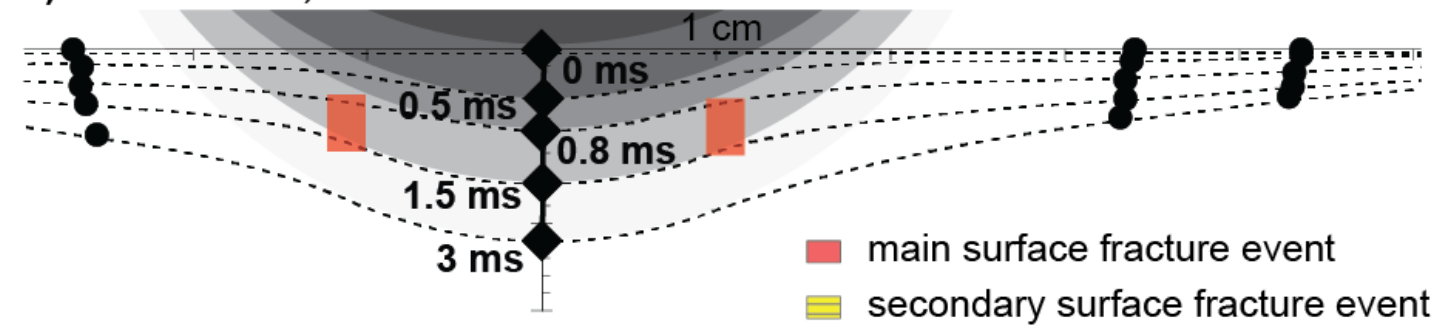

b) steel ball $45^{\circ}, 10 \mathrm{~J}$
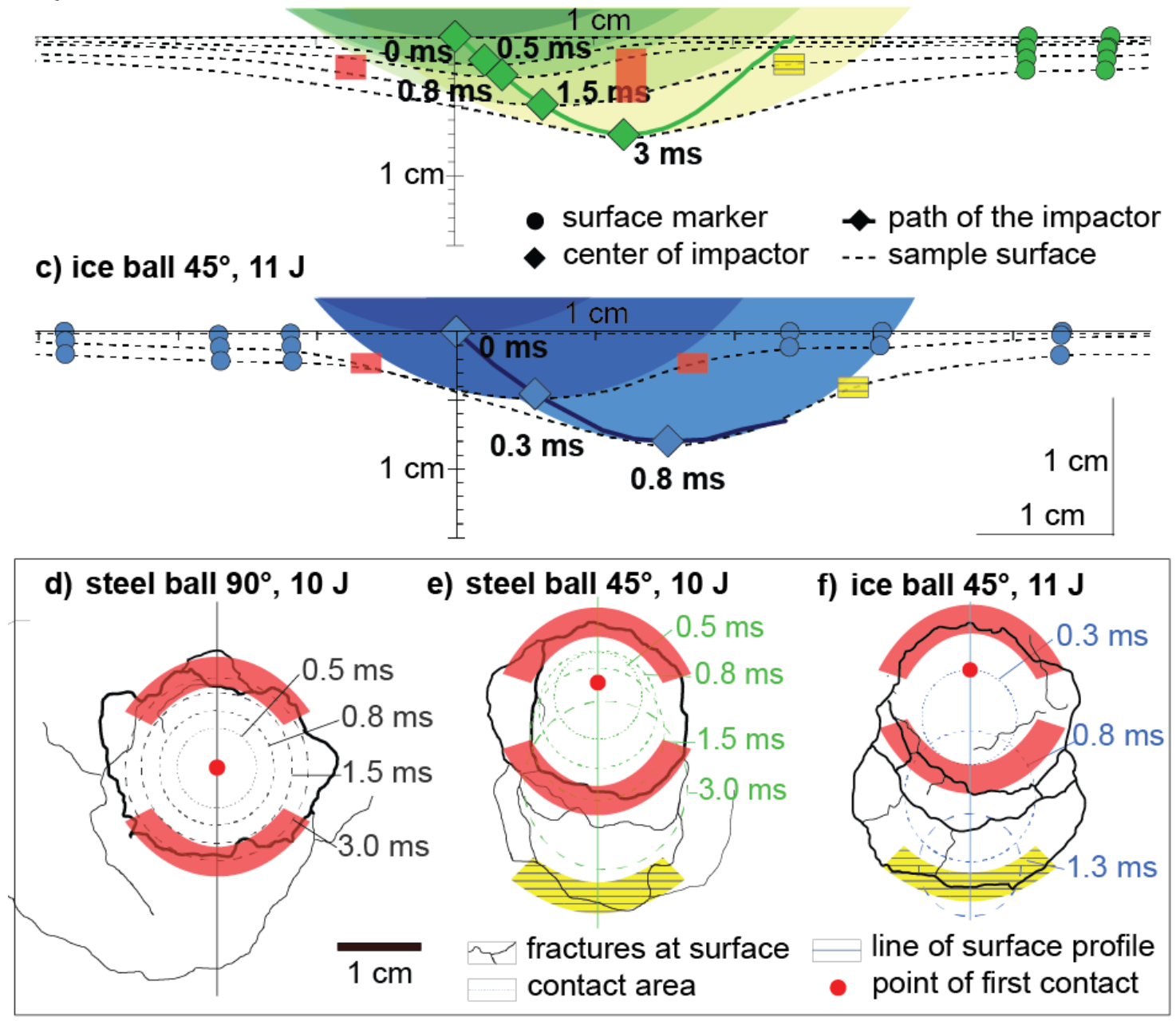

Figure 10: Link between vertical profile ( $a-c)$ and surface fracture pattern (d-f) for the different impact tests. The ETICS surface breaks at the point of highest deflection in the depression (colored in red, $a-d$ ). The time of fracturing coincides with a temporal plateau in vertical surface marker movement (Figure 5). In the $45^{\circ}$ impact tests further semi-circular surface fractures form at later stages of the impact (yellow markings) caused by the shifting of the point of maximum indentation during the impact. Contact surface areas at different times are indicated by dotted circles ( $d$-f). 
Shortly after this main surface fracture event (Figure 10), the inward movement of the surface markers stops (see section 3.2.) forming aforementioned plateau (Figure 7). The central ETICS part just below the impactor continues to deflect vertically, while the outer part remains at a constant position. The generation of the fracture decouples the movement of the outer sample zone from the agitation of the center. Note that signal of fracture formation can be detected by the stopping of the markers inward movement only shortly after fracture formation, as the surface markers' movement at a distance from the fracture is slightly delayed caused by the signal velocity in the ETICS material (see retardation shift, Figure 7, also occurring between the impactors first contact with the sample surface and the first marker movement).

After a certain fracture opening and progressive ETICS extension, the mesh tightens and thus overbridges the stress decoupling by the fracture in the base coat. This leads to a further activation of the vertical displacement of the outer sample zone (outside of the surface ring fracture) at higher indentation depths, which is observable for high energy impacts only (Figure 7). Tightening of the mesh occurs not occurring instantaneously, indicating that the woven mesh structure allows some early extension despite the high elastic modulus of the glass fibers building the mesh framework. The mesh has an enhanced elasticity compared to the base coat and can thus not bear stresses shortly after impact and cannot prevent early indentation damage in the base coat. This interpretation fits the observation that significant mesh parallel fractures occur at high impact energies [24], resulting in shearing and decoupling between mesh and base coat interior.

In the $90^{\circ}$ steel ball experiments, the point of maximum indentation stays at the same position at the sample surface throughout the whole impact progress leading to a symmetric damage pattern [24]. After the initial formation of the main ring fracture, the ball penetrates further leading to increasing internal fracturing. Although the base- and top coat are fractured, parts of the strain are still transferred to the outer parts of the sample as the reinforcement mesh does not rupture at the investigated energy range and further tightens. At the outer parts of the sample, this strain leads to the formation of additional circular surface fractures (small fractures with large radius in Figure $10)$. Note that such fractures caused by strain transformation via the mesh are only observed at impact energies exceeding $6 \mathrm{~J}$ [24].

\section{Secondary fractures in $45^{\circ}$ setups}

In the $45^{\circ}$ setups, secondary semi-circular fractures form south of the main ring fracture. In these tests, the ball slides along the sample surface and starts to rotate, shortly after the first surface contact (Figure $3 \mathrm{~b} \& \mathrm{c}$ ). Therefore, the point of maximum indentation shifts horizontally during impact (Figure 10). This leads to a shift in the stress field along the path of the impactor, which forces the system to subsequently form new fractures in the direction of the surface parallel movement of the ball. After the formation of the main surface ring fracture at an indentation depth of 3-4 mm, further strong semi-circular surface fractures form ([24]; secondary surface fractures, highlighted by the yellow square in Figure 10).

\section{Depressions}

Depressions in the ETICS document the irreversible deformation and document the plastic deformation in the EPS insulation plate [24]. During the impact, the upper part of the EPS is compressed by the high indentation amplitude of the impactor above the elastic yield of the material. As the base coat and top coat are fractured, the pull forces of the elastic mesh are not strong enough to bring the ETICS surface back into its original horizontal position. 


\subsection{Damaging mechanism}

Impacts are expected to lead to strong compressional forces at the impact center as well as to extensional forces in the regions around the impact. Our results indicate that the material's extensional characteristics are much more relevant in light of material failure and associated damage than compressive. This observation is in line with previous studies, which link a reduction in damage under dynamic loading with an increase in ductility and tensile strength [30,31]. [25] additionally highlight the importance of the capacity of the mortar to absorb and dissipate the impact energy. Results available from our tests allow for the first time to disentangle leading damage mechanisms during impact at ETICS by direct impact recording, which will help to decide, which materials (and material properties) will be best elastic accommodation of impact energy and therefore would be beneficial for a high impact resistance. In the following sections the importance of both, compressive and extensional strain and the associated stress states, is discussed in the context of the impact dynamics revealed by our experiments.

\section{Compressive strain/stress (point loading)}

In impact tests, compressive forces are expected to cause fractures at areas of highest compressive stress. Such areas occur at the center of the contact between ball and sample surface owing to the highest point loads. As a result, prominent fractures should be present at the center of the contact area if compressive stresses are the reason for fracture formation. However, none of our impact tests caused such visible compressional fractures (Figure $10 \mathrm{~d}-\mathrm{f}$ ) at the surface. Consequently, we conclude that compressional stresses are not the main reason for fracture formation.

Estimating the compressive stresses during impact using the total impact force divided by the contact area supports this argumentation (Figure 11a) although locally the compressive stress can be higher than the given average value calculated for the total contact area. During the impact process, the calculated compressive stress (Figure 11a) in all three test setups is significantly lower than the compressive strength of the base coats in ETICS (9 MPa according to own measurements in a compressive test of a $10 \times 30 \times 60 \mathrm{~mm}$ sample; $13 \mathrm{MPa}$ according to [7]). Furthermore, the low EModulus and low yield for plastic deformation of the EPS insulation plate prevent the building up high impact stresses exceeding the fracture strength of the base coat forcing a substantial amount of deformation to be accommodated in the EPS.
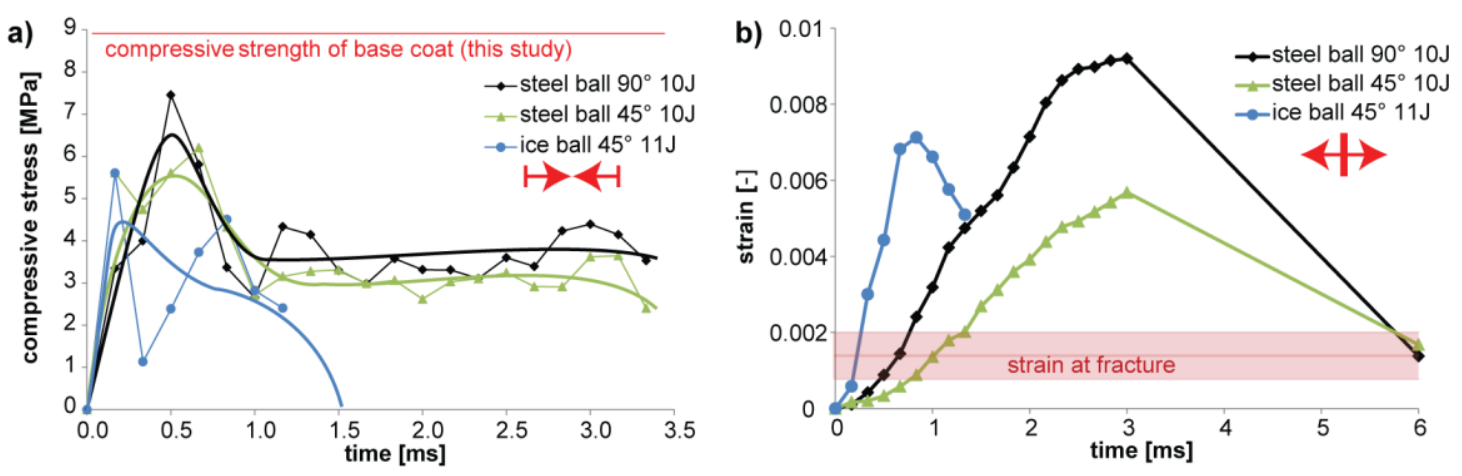

Figure 11: (a) Development of average compressive stress (pressure) during impact is lower than compressive strength of the base coat (indicated as straight line red); (b) Average extensional strain (of $20 \mathrm{~cm}$ sample surface as shown in Figure 5, strain $\left.=\left(l_{-} l_{0}\right) / l_{0}\right)$ during impact. Threshold strain for the onset of fracturing of the base coat (indicated by the straight line in red) is exceeded at an early stage of the impact. 


\section{Extensional strain and tensile stresses}

Flexural bending causes a local extension (Figure 11b) and associated tensile stresses in the region of the shoulders. It is this extension, where the tensile stresses exceed the tensile strength resulting in the formation of all externally visible and most of the internal fractures. The indentation amplitudes of the impactors are high exceeding in most cases the thickness of the protective render layer (Figure 11b). Consequently, the render layer strongly elongates horizontally as a result of the flexural bending of the surface during impact. For instance, the elongation of a $10 \mathrm{~J}$ (ice ball $11 \mathrm{~J}$ ) impact causes a calculated average stain that exceeds the extensional fracture formation strain (strain at fracture) of the base coat at which fractures formed in uniaxial experiments already shortly after impact (Figure $11 \mathrm{~b}$, steel ball $90^{\circ}$ at $0.4-0.8 \mathrm{~ms}$, steel ball $45^{\circ}$ at $0.6-1.4 \mathrm{~ms}$, ice ball $45^{\circ}$ at 0.1-0.3 ms, base coat strain at fracture provided in [32]). This critical elongation is reached at an indentation depth of about $2+/-1 \mathrm{~mm}(2+/-1 \mathrm{~J}$ kinetic energy of the impactor transferred to the system). Consequently, extensional fractures in the base coat must form at this early time at relatively low impact energies $(<2 \mathrm{~J})$ as a reaction to the movement. They might even form earlier as the local strain at bending regions is higher than the average bulk strain. Owing to increasing tensile strains with depth, the nucleation site of the fracturing is located at the base of the base coat directly below the ball (see also [24]). At a later stage of the impact progress, the surface fractures form in areas of high bending in the outer bending region (see 4.2.). After the main surface fracture has formed, the render is separated along this fracture. Only the reinforcement mesh keeps the connection between the region below the impactor and the outer part of the render. This behavior results in a shift from more flexural bending to uniaxial extension along the mesh (Figure 8). Consequently, fractures along the mesh are increasing at high energies. Extensional strain and associated high tensile stresses but low tensile strengths of ETICS represents the main reason for material failure in hail stone impacts. Preventing this damage will demand ETICS materials with high flexibility (strain at fracture) and tensile strength.

\section{Conclusions}

\subsection{Validation of established impact tests (ETAG 004 and VKF P. 8)}

The investigated test setups (ETAG 004 and VKF P. 8) are comparable regarding the mechanisms forming the damage in ETICS. In both setups the plastic deformation in the EPS forming the depression and high extensional strain causing the surface fracturing are the dominating damaging features. It is therefore appropriate to use a simplified $90^{\circ}$ test according to ETAG 004 in order to evaluate the impact resistance of ETICS. This very economic test setup is particularly suitable for product development. However, the test implements (1) a non-realistic low impactor speed, (2) an inappropriate friction, (3) no shift of the point of maximum indentation during impact, (4) no wetted sample surface or (5) fragmentation of the ice ball during impact as well as (6) unrealistically high impact depth when compared to hail ball impacts. In the investigated ETICS, ice ball tests (VKF P. No. 8) lead to up to two times higher fracture strengths when compared to the ETAG 004 setting. This higher impact resistance is most likely caused by the lower total impact depths at equal impact energy, which causes lower extensional strain at the sample surface.

The ice ball impact test according to VKF provides more realistic conditions and is advisable for final admission of ETICS or other surfaces regarding hail impact resistance. However, it is still lacking several features of natural hail storms like the irregular shape and surface of the hail stones, multiple angles, a temperature drop before the impact event caused by the change in weather conditions [33] and multiple impacts at the same spot [24]. 


\subsection{Impact dynamics and implications for ETICS hail resistance}

Using high-speed-camera recordings, the importance of extensional strain for damage formation is demonstrated. A high impact depth leads to an elongation of the render, which is much higher than its strain at first fracture formation in tensional uniaxial experiments. First extensional fractures (invisible from the surface) form early during impact at the base of the base coat below the impactor. The visible surface fractures evolve later at an indentation depth of about 3-4 mm, when strain concentrates at the depression shoulders. Oblique impacts result in considerable movement parallel to the surface resulting in secondary semi-circular fractures, an elongated surface damage and a considerable lower indentation depth. The latter is responsible for the lower damage threshold energy in ice ball impacts. No indications for pure compressional fractures were identified.

All fractures form due to extensional strain. Consequently, flexible render layer materials with a high fracture strain are favorable in the development of ETICS with high impact resistance. This adaptation could prevent the fracture formation in bending regions. For example mortar formulations with a high amount of organic binders could be used, as they provide the needed higher flexibility. However, high flexibility in the render leads to high indentation depth and an insufficient distribution of impact energy. To prevent this, stiff and fast reacting reinforcement meshes and insulation materials with high elastic moduli and good restoring capacities could be used.

\section{Acknowledgments}

We acknowledge the Commission for Technology and Innovation for financial support of Project No 13030.1 PFIW-IW, Flüeler Polymer Consulting (Dübendorf, Switzerland) for conducting the ice ball tests and the Institute for Medical and Analytical Technologies (FHNW, CH-Muttenz) for kindly supporting us with the high-speed-camera.

\section{References}

[1] Stucki M, Egli T. Elementarschutzregister Hagel. In:. Tech. rep., Präventionsstiftung der kantonalen Gebäudeversicherungen; 2007.

[2] Jakob M, Mosbacher R, Glatthard T. Wärmeschutz bei Wohnbauten: Kosten und Nutzen, on behalf of Bundesamt für Energie BFE. Bern 2003.

[3] Anastaselos D, Giama E, Papadopoulos AM. An assessment tool for the energy, economic and environmental evaluation of thermal insulation solutions. Energy and Buildings 2009;41:1165-71. doi:10.1016/j.enbuild.2009.06.003.

[4] Griciutė G, Bliūdžius R, Norvaišienė R. The durability test method for external thermal insulation composite system used in cold and wet climate countries. Journal of Sustainable Architecture and Civil Engineering 2013;1:50-6. doi:10.5755/j01.sace.1.2.2778.

[5] Künzel H, Künzel HM, Sedlbauer K. Long-term performance of external thermal insulation systems (etics). ACTA Architectura 2006;5:11-24. 
[6] Canada Mortagage and Housing Corporation (CMHC). Exterior Insulation and Finish Systems (Best Practice Guide, Building Technology). European Organisation for Technical Approvals (EOTA), Brussels 2004.

[7] Nilica R, Harmuth H. Mechanical and fracture mechanical characterization of building materials used for external thermal insulation composite systems. Cement and Concrete Research 2005;35:1641-5. doi:10.1016/j.cemconres.2005.04.001.

[8] Neumann H-H. Praxis-handbuch wärmedämm-verbundsysteme: Baustoffkunde, verarbeitung, schäden, sanierung. Müller; 2009.

[9] Papadopoulos A. State of the art in thermal insulation materials and aims for future developments. Energy and Buildings 2005;37:77-86. doi:10.1016/j.enbuild.2004.05.006.

[10] European Parliament. Directive 2009/28/EC of the European Parliament and of the council of 23 April 2009 on the promotion of the use of energy from renewable sources and amending and subsequently repealing Directives 2001/77/EC and 2003/30/EC 2009;2008:16-62.

[11] SFA. Bundesgesetz über die Reduktion der CO2-Emissionen (CO2-Gesetz). Swiss Federal Assembly SFA 2011;Bern.

[12] BFE. Analyse des schweizerischen Energieverbrauchs 2000-2014 nach Verwendungszwecken. Bundesamt Für Energie Schweiz 2015.

[13] Paterson DA, Sankaran R. Hail impact on building envelopes. Journal of Wind Engineering and Industrial Aerodynamics 1994;53:229-46. doi:10.1016/0167-6105(94)90028-0.

[14] Kunz M, Sander J, Kottmeier C. Recent trends of thunderstorm and hailstorm frequency and their relation to atmospheric characteristics in southwest Germany. International Journal of Climatology 2009;29:2283-97. doi:10.1002/joc.1865.

[15] Hohl R, Schiesser HH, Aller D. Hailfall: The relationship between radar-derived hail kinetic energy and hail damage to buildings. Atmospheric Research 2002;63:177-207. doi:10.1016/s01698095(02)00059-5.

[16] Bienert S. Extreme weather events and property values. Urban Land Institute: Europe Policy \& Practice Committee Report 2014.

[17] Nicolet P, Voumard J, Choffet M, Demierre J, Imhof M. Analysis and modeling of a hail event consequences on a building portfolio. In:. EGU general assembly conference abstracts, vol. 16, 2014, p. 10447.

[18] Flueler P, Stucki M, Guastala F, Egli T. Hail impact resistant building materials, testing, evaluation and classification. Proceedings of 11th DBMC Durability of Building Materials, Istanbul Turkey 2008:249-65.

[19] Schlüpfer W. Nicht an jedem Schaden ist nur der Hagel schuld. Appilca 2014.

[20] Zirkelbach D, Künzel HM, Slanina P. Einfluss von Undichtheiten bei der Sanierung von Plattenbauten mit Wärmedämm-Verbundsystemen. WTA-Almanach 2008.

[21] Heymsfield AJ, Giammanco IM, Wright R. Terminal velocities and kinetic energies of natural hailstones. Geophysical Research Letters 2014;41:8666-72. doi:10.1002/2014gl062324. 
[22] ETAG 004. Guideline for European Technical Approval of External Thermal Insulation Composite Systems With Rendering. European Organisation for Technical Approvals (EOTA), Brussels 2011.

[23] VKF. Prüfbestimmung Nr. 08: Putz auf Aussendämmung. Vereinigung Kantonaler Feuerversicherungen, Schweizerisches Hagelschutzregister HSR, Bern 2011.

[24] Steinbauer V, Zurbriggen R and Buehler T, Herwegh M. Impact Microstructures of External Thermal Insulation Composite Systems (ETICS). Cement and Concrete Composites, Submitted 2017: in review.

[25] Petit J-Y, Wirquin E. Characterising impact resistance of latex-cement mortars for external insulation systems. Advances in Cement Research 2014;26:21-8.

[26] Kille R. Spachtelzahnungen für Bodenbelag-, Parkett- und Fliesenarbeiten. TKB-Merkblatt 6, Industrieverband Klebstoffe EV, Düsseldorf (Germany) 2007.

[27] Schulson EM. The structure and mechanical behavior of ice. JOM 1999;51:21-7. doi:10.1007/s11837-999-0206-4.

[28] Petrovic J. Review mechanical properties of ice and snow. Journal of Materials Science 2003;38:1-6.

[29] Giammanco IM, Brown TM. Characteristics of severe hail 2012: Pilot field study: Data analysis summary. Insurance Institute for Business and Home Safety IBHS 2013.

[30] Dancygier A, Yankelevsky D. High strength concrete response to hard projectile impact. International Journal of Impact Engineering 1996;18:583-99. doi:10.1016/0734-743x(95)00063-g.

[31] Farnam Y, Mohammadi S, Shekarchi M. Experimental and numerical investigations of low velocity impact behavior of high-performance fiber-reinforced cement based composite. International Journal of Impact Engineering 2010;37:220-9. doi:10.1016/j.ijimpeng.2009.08.006.

[32] Raso RA, Kaufmann J, Steinbauer V, Eberhard L, Bühler T, Pieles U, et al. Relating strength properties with impact resistance of external thermal insulation composite systems. Construction \& Building Materials 2016: in review.

[33] Crenshaw V, Koontz JD. Simulated hail damage and impact resistance test procedures for roof coverings and membranes. RCI Interface 2001;19:5-10. 